\title{
Cell-based models to study GNRH neuron physiology
}

\begin{abstract}
The chance to produce in vitro cultures of neuronal cells has been fundamental for neurobiological studies. The advancing of our understanding on the physiology of the nervous system has been strongly supported by the in vitro cultures of neuronal cells, as both primary cultures and oncogene-mediated immortalized cells.

Among the hypothalamic neuroendocrine neurons, gonadotropin-releasing hormone (GnRH) expressing neurons represent a unique class; they are generated outside the brain, in the olfactory placode, and during embryonic life they move by tangential neurophilic migration, along terminal and vomeronasal nerves, to the septal-hypothalamic region. At this level GnRH neurons undergo terminal differentiation and axonal elongation to make contacts with the pituitary portal vessels in which they start releasing the decapeptide $\mathrm{GnRH}$ in a pulsatile fashion, to modulate the function of the reproductive axis.

However, the investigation of GnRH neurons has been hindered by their low abundance (800-1200) and their peculiar anatomical distribution. The study of these neurons has been forwarded since ' 90 by the availability of cell lines of immortalized mouse GnRHexpressing neurons (GT1 and GN cells lines); more later, other cell lines of GnRH-releasing neurons were established from human fetal olfactory neuroblasts and rat adult hypothalamic neurons under conditional immortalization. Later, different in vitro models for the study of human GnRH neurons have been described; they include organotypic cultures of olfactory placode or hypothalamic tissue and primary cultures enriched in GnRH neurons. More recently, an new in vitro model of $\mathrm{GnRH}$ neurons has been obtained from primary human fetal hypothalamic cell cultures. A new impulse to the study of these peculiar neurons in physiological, as well as in pathological conditions, will come from the already promising development of GnRH-secreting neurons from neuronal stem cells and induced pluripotent stem cells (iPSCs)
\end{abstract}

Keywords: gonadotropin releasing hormone, physiology, cell-based model, stem cells, rodents, human
Volume 3 Issue $6-2017$

\author{
Chiara Rigobello, Roberto Maggi \\ Department of Pharmacological and Biomolecular Sciences, \\ Università degli Studi di Milano, Italy
}

\section{Correspondence: Roberto Maggi, Department of}

Pharmacological and Biomolecular Sciences, Università degli Studi di Milano,Via G Balzaretti, 9, 20133 Milano (MI), Italy, Te +3902 5031 8233, Fax +390250318204,

Email roberto.maggi@unimi.it

Received: March 03, 2017| Published: July 03, 2017
Abbreviations: SV40, symian virus 40; Tet-On, tetracycline inducible expression systems; HIV, human immunodeficiency virus; SMAD, small mother against decapentaplegic proteins; FGF8, fibroblast growth factor 8; Notch, neurogenic locus notch homolog protein; BMP4, bone morphogenetic protein 4

\section{Introduction}

The study of the Gonadotropin Releasing Hormone (GnRH)secreting neurons in animal models is generally hindered by their peculiar development and anatomical distribution. Several subpopulations of GnRH neurons have been described; in addition, they born from the embryonic olfactory region (olfactory placode), migrate during a developmental narrow window of time (from embryonic day 11 to 18 , in rodents and about in six weeks in human) and the GnRH neurons involved in the reproductive functions are very limited in number (from 800 in mouse to more than 2000 in human) ${ }^{1,2}$ and scattered into the septo/hypothalamic region in adulthood.

The study of the factors that are directly involved in the mechanisms controlling the development and function of $\mathrm{GnRH}$ neurons requires the possibility to work in well-defined experimental conditions in which one can dissect out the specific actions of the several factors investigated.

\section{Discussion}

\section{Rodent derived models}

GnRH neuron immortalization: Actually, the study of $\mathrm{GnRH}$ neurons in the last decades has been facilitated by the development of cell models of isolated GnRH- secreting neurons.

We're more than 25years from the establishment by Pamela Mellon and Sally Radovick groups of the first cell lines of immortalized mouse GnRH neurons. The different cell lines, named GT1 cells (which include GT1-1, -3 and -7 subclones) ${ }^{3}$ and GN cells (with GN10, GN11 and NLT subclones $)^{4}$ have been obtained by genetically targeted tumorigenesis of GnRH neurons in mice using, respectively, the rat and human 5' regulatory region of the GnRH gene to control the expression of the SV40 large T-antigen oncogene (Figure 1).

Biochemical and immunological studies have shown that both cell lines express neuronal markers, and retain the biological features of GnRH-secreting neurons.

Later, we demonstrated for the first time that GN11 cells show a strong responses in vitro to several chemo-attractants with migratory characteristics and estimated migration speed $(10 \mu \mathrm{m} / \mathrm{h})$ very similar to that of brain neurons: ${ }^{5-8}$ on the contrary, GT1-7 cells do not show significant migratory activity, unless under specific conditions. ${ }^{9}$ 


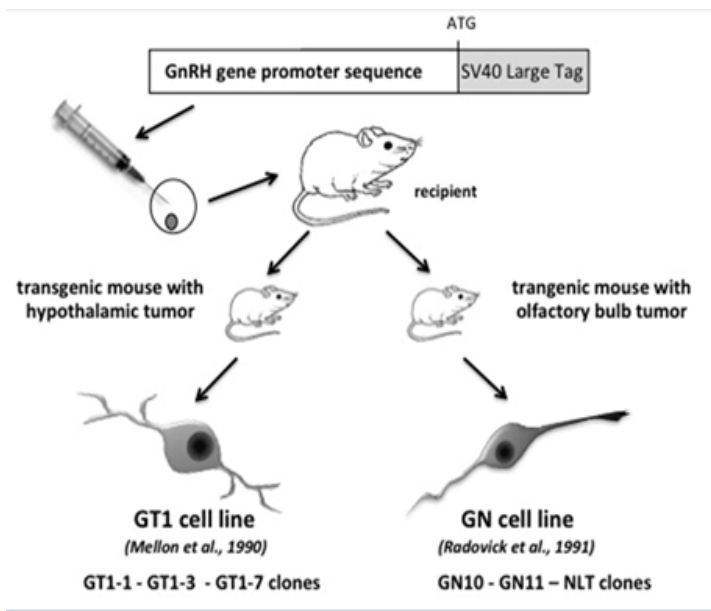

Figure I Schematic representation of the development of GTI and GN cell lines.

These evidences are suggestive of GT1-7 and GN11 neurons as representative of differentiated post-migratory and immature migratory GnRH neurons, respectively. ${ }^{5,6}$ Moreover, the use of these models in more than 370 published studies (source PubMed) and the finding of a number of similarities with normal GnRH neurons "in vivo",, $10-12$ confirm that immortalized GnRH neurons could be considered an adequate model to study the biology of GnRH-secreting neurons in isolated conditions.

Thanks to the in vitro migratory activity of GN11 cells, we have provided the first experimental evidence that the product of ANOS1 gene (anosmin 1) could exert a direct stimulatory action on the migration of GnRH neurons. ${ }^{7}$ ANOS1 is the first gene identified as causative of the Kallmann's Syndrome (KS), a genetic hypogonadotropic hypogonadism due to GnRH deficiency. ${ }^{13}$ GN11 cells have been also successfully used to investigate, at the cell level, or to confirm the role of several factors found to affect the migration of wild type mouse GnRH neurons. ${ }^{14-20}$

GT1 cell clones have been widely used to study the electrophysiological characteristics of $\mathrm{GnRH}$ neurons that lead to the pulsatile release of the decapeptide ${ }^{21,22}$ as well as the transcriptional control of $\mathrm{GnRH}$ gene and the effects of several regulators of $\mathrm{GnRH}$ secretion. ${ }^{23-26}$

GT1 and GN derived neurons have been also used to evaluate many physiological mechanisms involving GnRH. ${ }^{27}$ Recently, GnRH neurons have been proposed as a target of energy sensors and immortalized neurons offer a useful tool to study the effects of altered energy/metabolic state on GnRH expression or neuronal migration. Both GT1-7 and GN11 express insulin receptors, that mediate glucose uptake and phosphorylation of Akt through IP3kinase activation. GT17 cells has been also used to develop an in vitro model of neuronal insulin resistance. ${ }^{28}$ The energy sensor adenosine monophosphateactivated protein kinase (AMPK) is also expressed in both GT1-7 and GN11 and it is involved in the regulation of a Glucose Excite-type glucose-sensing behavior and cell migration, respectively. ${ }^{29,30}$

On the whole, these cell lines represent ideal models for testing the role of factors involved in GnRH neuron survival, differentiation and migration in controlled in vitro conditions, offering the unique opportunity to induce genetic modifications of isolated $\mathrm{GnRH}$ neurons as well as to expose them to altered metabolic environments that may be causative of several diseases.

In order to ascertain the potential direct effect of insulin, another cell line of rat GnRH neurons has been described by Salvi et al..$^{31}$ These neurons $(\mathrm{Gnv}-3)$ have been selected from twelve different clonal cell lines that were derived from primary cultures of adult (10-12weekold female) rat hypothalamic neurons by conditional immortalization; these cells retain many of their mature phenotypic characteristics of mature GnRH neurons. In contrast to GT1 cells, the GnV cells are under a conditional immortalization process obtained using a TetOn system (55) transfected in primary neurons by lentiviral vectors derived from HIV; these vectors are able to transduce non dividing, post mitotic neurons, and have been successfully used in other studies. ${ }^{31,32}$

Immortalized GnRH neurons offer many advantages in term of stability, repeatability, easiness of culture and gene transfection that make them useful for complex cell biology studies.

Primary tissue and cell cultures: To circumvent the possible problems linked to the oncogene-derived immortalization of the cells, slice explant culture method was also developed to study adult GnRH neurons. ${ }^{33}$ In particular, organotypic cultures of explants of the hypothalamus or the preoptic area to study adult GnRH neurons have yielded interesting results on neuronal function and decapeptide secretion. ${ }^{34,35} \mathrm{GnRH}$ neurons in tissue explants retain features of their in vivo counterparts and maintain many physiological connections with neighboring cells (neurons or glial cells) but they were not so efficient to directly test isolated GnRH neurons, mainly because of their post-hoc identification. ${ }^{36}$

The embryonic expression of $\mathrm{GnRH}$ gene allowed the setup of cultures of olfactory placode explants. ${ }^{37-42}$ This model was developed for mouse, rat, sheep and Rhesus monkey and it presents several advantages since GnRH neurons in the placode have not been in contact with hypothalamic neurons or glial cells and therefore they have not still established a physiological state of secretion. However, this type of culture represents an interesting model limited for studying the mechanisms underlying the onset and the control of pulsatility in GnRH neurons.

The difficulties to work on isolated native GnRH neurons have been overcame by efficient procedures of cell isolation and cultures.

Several studies have described the isolation of primary cultures of hypothalamic and of nasal placodes derived neurons. ${ }^{41,43,44}$

Primary culture of GnRH neurons derived from embryonic olfactory placode has been obtained from different animal species (mouse, rat, sheep and monkey) and used to study several mechanisms implied in GnRH neuron development and function. ${ }^{37,38,40,45,46}$ In these cultures olfactory neurons and olfactory ensheathing cells are maintained and therefore GnRH neurons result still mixed with other cell populations.

To facilitate the study of GnRH neurons in tissue explants, transgenic mice with jellyfish reporter, green fluorescent protein (GFP), targeted to GnRH neurons (GFP-GnRH mice) have been developed. ${ }^{47}$ Primary cultures of GnRH neurons have also obtained by dispersion of fetal olfactory tissue derived from of GFP-GnRH mice. ${ }^{48,49}$ The presence of GnRH neurons expressing GFP in tissue explant or mixed cell cultures allows to identify living GnRH neurons in tissue slice preparations before and during the experiments; this offers significant experimental advantages for biochemical or electrophysiological experiments..$^{50,51}$

\section{Human-derived models}

The complete inaccessibility of human GnRH neurons also in ex vivo studies rose the need of a specific cell-based model. 
In 1995 it has been reported the isolation, characterization, and cloning of neuroblast cell lines obtained from olfactory epithelium of 8- to 12 week-old human fetuses that showed typical neuronal and olfactory properties and were able to respond to odors, ${ }^{52}$ later it has been demonstrated that one such clone (FNC-B4) produced GnRH, it was responsive to sex steroids and sensitive to odorants in terms of GnRH production. ${ }^{53}$ FNC-B4 showed migratory activity in vitro ${ }^{54}$ and have been used in several protocols of investigation on human $\mathrm{GnRH}$ neuron functions. ${ }^{55-57}$ Moreover, these cells express several genes relevant for $\mathrm{GnRH}$ neuron function as kisspeptin and its receptor, sex steroid, leptin and FGF receptors. ${ }^{56,58}$

More recently, another in vitro model of GnRH neurons of human origin was recently obtained from primary human fetal hypothalamic cell cultures isolated from brain of three 12 week-old fetuses (hfHypo cells). ${ }^{59}$ These neurons were found to be responsive to kisspeptin and were successfully used to investigate the effects of pro inflammatory cytokines on their biological properties, as previously observed by in vivo experiments. The hf Hypo cells represent a novel tool for in vitro investigations on the human GnRH neuron biology and its involvement in hypothalamic inflammation, a process that has been implicated in programming systemic aging. ${ }^{60}$

Neuronal stem cells and induced pluripotent stem cells (iPSCs)derived cell models: The future improvement of the study of GnRH neuron pathophysiology might stem from the establishment of in vitro models derived from neuronal multipotent or pluripotent precursor cells. Salvi et al. ${ }^{31}$ isolated NSCs from rat embryonic (E18) and adult hypothalamus; these cells grow in suspension as neurospheres and once differentiated they exhibit a GnRH-like neuronal subtype ${ }^{61}$ possibly indicating that they represent a GnRH-committed population of olfactory placode-derived precursors.

However, isolation and characterization of a cell line of embryonic stem cells (AC1) from E14 mouse hypothalamic region (when GnRH neurons are still migrating from the olfactory region) failed to show GnRH expression also under high-efficiency neuronal differentiating conditions. ${ }^{8}$ These results suggest a clear difficulty to isolate GnRHcommitted NSC to be easily used for in vitro studies.

Recently, a three-step protocol to differentiate human pluripotent stem cells (hPSCs) into GnRH-secreting neurons has been reported. ${ }^{62}$ The hPSCs were first differentiated to anterior neural progenitor cells (NPCs) by dual SMAD inhibition, then exposed to FGF8, a factor involved in GnRH neuron ontogeny, and finally matured to neurons by Notch inhibitor. These cells have been shown to express the GnRH gene and to release the GnRH decapeptide into the culture medium. The protocol was found to be reproducible both in human Embryonic Stem Cells (ESC) and iPScs.

Finally, it has been reported the efficient generation of GnRHsecreting neurons by directed differentiation of human ESC with a an alternative protocol. ${ }^{63}$ These neurons have been generated by a longterm exposure of ESC to BMP4 inhibition to induce intermediate NPCs, which have been then terminally specificated with FGF8 and Notch inhibitor. The resulting neurons express and release GnRH, display a neuroendocrine gene expression pattern and present spontaneous calcium transients that can be stimulated by kisspeptin. Of interest, similar GnRH cells have been obtained from inducedPluripotent Stem Cells derived by a KS patient.

Once better characterized to be responsive to known regulatory signals, these in vitro generated GnRH expressing cells will open new perspectives in the investigation of the molecular mechanisms underlying the development and function of human GnRH neurons.

\section{Conclusion}

The development of cell-based models of GnRH neurons represents an ideal tool for testing the role of the factors involved in GnRH neuron survival, differentiation and migration in controlled in vitro conditions and offers the unique opportunity to induce genetic modifications as well as to test the effects of altered metabolic environments.

The study of the isolated GnRH neurons is of true neurobiological and neuroendocrinological interest. It has potential implications not only for the investigation of the molecular mechanisms leading to the development of reproductive functions, as well as their related diseases (such as central hypogonadotropic hypogonadisms), but also for the variable, concomitant neurological defects occurring in addition to the overt infertility and for the screening of possible therapeutic molecules. Not least, the study of the molecular cues that affect the development and functions of GnRH neurons may also provide novel insights on common biochemical events controlling the physiology of other neuronal populations.

\section{Acknowledgements}

We thank Dr. Patrizia Limonta for the critical reading of the manuscript. Supported by Università degli Studi di Milano (Research Support Plan, line 2, action B 2017-18)

\section{Conflict of interest}

The author certifies that they have NO affiliations with or involvement in any organization or entity with any financial or nonfinancial interest in the subject matter or materials discussed in this manuscript.

\section{References}

1. Wray S, Grant P, Gainer H. Evidence that cells expressing luteinizing hormone-releasing hormone mRNA in the mouse are derived from progenitor cells in the olfactory placode. Proc Natl Acad Sci USA. 1989;86(20):8132-8136.

2. Casoni F, Malone SA, Belle M, et al. Development of the neurons controlling fertility in humans: new insights from 3D imaging and transparent fetal brains. Development. 2016;143(21):3969-3981.

3. Mellon PL, Windle JJ, Goldsmith PC, et al. Immortalization of hypothalamic $\mathrm{GnRH}$ neurons by genetically targeted tumorigenesis. Neuron. 1990;5(1):1-10.

4. Radovick S, Wray S, Lee E, et al. Migratory arrest of gonadotropinreleasing hormone neurons in transgenic mice. Proc Natl Acad Sci USA. 1991;88(8):3402-3406.

5. Maggi R, Pimpinelli F, Molteni L, et al. Immortalized luteinizing hormone-releasing hormone neurons show a different migratory activity in vitro. Endocrinology. 2000;141(6):2105-2112.

6. Pimpinelli F, Redaelli E, Restano Cassulini R, et al. Depolarization differentially affects the secretory and migratory properties of two cell lines of immortalized luteinizing hormone-releasing hormone (LHRH) neurons. Eur J Neurosci. 2003;18(6):1410-1418.

7. Cariboni A, Pimpinelli F, Colamarino S, et al. The product of X-linked Kallmann's syndrome gene (KAL1) affects the migratory activity of gonadotropin-releasing hormone ( $\mathrm{GnRH})$-producing neurons. Hum Mol Genet. 2004;13(22):2781-2791.

8. Zito A, Cartelli D, Cappelletti G, et al. Neuritin 1 promotes neuronal migration. Brain Struct Funct. 2014;219(1):105-118.

9. Choe Y, Jung H, Khang I, et al. Selective roles of protein kinase C isoforms on cell motility of GT1 immortalized hypothalamic neurones. J Neuroendocrinol. 2003;15(5):508-515. 
10. Wetsel WC, Liposits Z, Seidah NG, et al. Expression of candidate pro-GnRH processing enzymes in rat hypothalamus and an immortalized hypothalamic neuronal cell line. Neuroendocrinology. 1995;62(2):166-177.

11. Gore AC, Roberts JL. Regulation of gonadotropin-releasing hormone gene expression in vivo and in vitro. Front Neuroendocrinol. 1997;18(2):209-245.

12. Pimpinelli F, Parenti M, Guzzi F, et al. Presence of delta opioid receptors on a subset of hypothalamic gonadotropin releasing hormone $(\mathrm{GnRH})$ neurons. Brain Res. 2006;1070(1):15-23.

13. Cariboni A, Maggi R. Kallmann's syndrome, a neuronal migration defect. Cell Mol Life Sci. 2006;63(21):2512-2526.

14. Dondi D, Piccolella M, Messi E, et al. Expression and differential effects of the activation of glucocorticoid receptors in mouse gonadotropin-releasing hormone neurons. Neuroendocrinology. 2005;82(3-4):151-163.

15. Cariboni A, Rakic S, Liapi A, et al. Reelin provides an inhibitory signal in the migration of gonadotropin-releasing hormone neurons. Development. 2005;132(21):4709-4718.

16. Cariboni A, Hickok J, Rakic S, et al. Neuropilins and their ligands are important in the migration of gonadotropin-releasing hormone neurons. J Neurosci. 2007;27(9):2387-2395.

17. Magni P, Dozio E, Ruscica M, et al. Leukemia inhibitory factor induces the chemomigration of immortalized gonadotropin-releasing hormone neurons through the independent activation of the Janus kinase/signal transducer and activator of transcription 3, mitogenactivated protein kinase/extracellularly regulated kinase $1 / 2$, and phosphatidylinositol 3-kinase/Akt signaling pathways. Mol Endocrinol. 2007;21(5):1163-1174.

18. Cariboni A, Andre V, Chauvet S, et al. Dysfunctional SEMA3E signaling underlies gonadotropin-releasing hormone neuron deficiency in Kallmann syndrome. J Clin Invest. 2015;125(6):2413-2428.

19. Vastagh C, Schwirtlich M, Kwakowsky A, et al. The spatiotemporal segregation of GAD forms defines distinct GABA signaling functions in the developing mouse olfactory system and provides novel insights into the origin and migration of GnRH neurons. Dev Neurobiol. 2015;75(3):249-270.

20. Hoffmann HM, Mellon PL. A small population of hypothalamic neurons govern fertility: the critical role of VAX1 in GnRH neuron development and fertility maintenance. Neurosci Commun (Houst). 2016.

21. Weiner RI, Martinez de la Escalera G. Pulsatile release of gonadotrophin releasing hormone $(\mathrm{GnRH})$ is an intrinsic property of GT1 GnRH neuronal cell lines. Hum Reprod. 1993;8 Suppl 2:13-17.

22. Costantin JL, Charles AC. Spontaneous action potentials initiate rhythmic intercellular calcium waves in immortalized hypothalamic (GT1-1) neurons. J Neurophysiol. 1999;82(1):429-435.

23. Maggi R, Pimpinelli F, Martini L, et al. Inhibition of luteinizing hormone-releasing hormone secretion by delta-opioid agonists in GT1-1 neuronal cells. Endocrinology. 1995;136(11):5177-5181.

24. Pimpinelli F, Rovati GE, Capra V, et al. Expression of prostacyclin receptors in luteinizing hormone-releasing hormone immortalized neurons: role in the control of hormone secretion. Endocrinology. 1999;140(1):171-177.

25. Nelson SB, Lawson MA, Kelley CG, et al. Neuron-specific expression of the rat gonadotropin-releasing hormone gene is conferred by interactions of a defined promoter element with the enhancer in GT1-7 cells. Mol Endocrinol. 2000;14(9):1509-1522.

26. Huang PP, Brusman LE, Iyer AK, et al. A Novel Gonadotropin-Releasing Hormone 1 (Gnrh1) Enhancer-Derived Noncoding RNA Regulates Gnrh1 Gene Expression in GnRH Neuronal Cell Models. PLoS One. 2016;11(7):e0158597.
27. Maggi R. Physiology of gonadotropin-releasing hormone (GnRH): beyond the control of reproductive functions. MOJ Anat \& Physiol. 2016;2(5):00063.

28. Yu IC, Lin HY, Liu NC, et al. Neuronal androgen receptor regulates insulin sensitivity via suppression of hypothalamic NF-kappa B-mediated PTP1B expression. Diabetes. 2013;62(2):411-423.

29. Beall C, Hamilton DL, Gallagher J, et al. Mouse hypothalamic GT17 cells demonstrate AMPK-dependent intrinsic glucose-sensing behaviour. Diabetologia. 2012;55(9):2432-2444.

30. Ruscica M, Dozio E, Steffani L, et al. Role of the energy sensor adenosine monophosphate-activated protein kinase in the regulation of immature gonadotropin-releasing hormone neuron migration. J Endocrinol Invest. 2011;34(10):e362-e368

31. Igaz P, Salvi R, Rey JP, et al. Effects of cytokines on gonadotropinreleasing hormone $(\mathrm{GnRH})$ gene expression in primary hypothalamic neurons and in GnRH neurons immortalized conditionally. Endocrinology. 2006;147(2):1037-1043.

32. Mansuy V, Geller S, Rey JP, et al. Phenotypic and molecular characterization of proliferating and differentiated GnRH-expressing GnV-3 cells. Mol Cell Endocrinol. 2011;332(1-2):97-105.

33. Wray S, Kusano K, Gainer H. Maintenance of LHRH and oxytocin neurons in slice explants cultured in serum-free media: effects of tetrodotoxin on gene expression. Neuroendocrinology. 1991;54(4):327-339.

34. Bourguignon JP, Gerard A, Alvarez Gonzalez ML, et al. Contro of pulsatile secretion of gonadotrophin releasing hormone from hypothalamic explants. Hum Reprod. 1993;8 Suppl 2:18-22.

35. Rasmussen DD. Episodic gonadotropin-releasing hormone release from the rat isolated median eminence in vitro. Neuroendocrinology. 1993;58(5):511-518.

36. Sim JA, Skynner MJ, Herbison AE. Direct regulation of postnatal GnRH neurons by the progesterone derivative allopregnanolone in the mouse. Endocrinology. 2001;142(10):4448-4453.

37. Wray S, Key S, Qualls R, et al. A subset of peripherin positive olfactory axons delineates the luteinizing hormone releasing hormone neuronal migratory pathway in developing mouse. Dev Biol. 1994;166(1):349-354

38. Daikoku S, Koide I, Chikamori Aoyama M, et al. Migration of LHRH neurons derived from the olfactory placode in rats. Arch Histol Cytol. 1993;56(4):353-370.

39. Maurer JA, Wray S. Luteinizing hormone-releasing hormone (LHRH) neurons maintained in hypothalamic slice explant cultures exhibit a rapid LHRH mRNA turnover rate. J Neurosci. 1997;17(24):9481-9491.

40. Duittoz AH, Batailler M, Caldani M. Primary cell culture of LHRH neurones from embryonic olfactory placode in the sheep (Ovis aries). $J$ Neuroendocrinol. 1997;9(9):669-675.

41. Terasawa E, Keen KL, Mogi K, et al. Pulsatile release of luteinizing hormone-releasing hormone (LHRH) in cultured LHRH neurons derived from the embryonic olfactory placode of the rhesus monkey. Endocrinology. 1991;140(3):1432-1441.

42. Funabashi T, Daikoku S, Shinohara K, et al. Pulsatile gonadotropinreleasing hormone $(\mathrm{GnRH})$ secretion is an inherent function of $\mathrm{GnRH}$ neurons, as revealed by the culture of medial olfactory placode obtained from embryonic rats. Neuroendocrinology. 2000;71(2):138-144.

43. Fueshko S, Wray S. LHRH cells migrate on peripherin fibers in embryonic olfactory explant cultures: an in vitro model for neurophilic neuronal migration. Dev Biol. 1994;166(1):331-348.

44. Constantin S, Caraty A, Wray S, et al. Development of gonadotropinreleasing hormone-1 secretion in mouse nasal explants. Endocrinology. 2009;150(7):3221-3227 
45. Terasawa E, Quanbeck CD, Schulz CA, et al. A primary cell culture system of luteinizing hormone releasing hormone neurons derived from embryonic olfactory placode in the rhesus monkey. Endocrinology. 1993;133(5):2379-2390.

46. Kusano K, Fueshko S, Gainer H, et al. Electrical and synaptic properties of embryonic luteinizing hormone-releasing hormone neurons in explant cultures. Proc Natl Acad Sci USA. 1995;92(9):3918-3922.

47. Spergel DJ, Kruth U, Hanley DF, et al. GABA- and glutamate-activated channels in green fluorescent protein-tagged gonadotropin-releasing hormone neurons in transgenic mice. JNeurosci. 1999;19(6):2037-2050.

48. Cronin AS, Horan TL, Spergel DJ, et al. Neurotrophic effects of BDNF on embryonic gonadotropin-releasing hormone (GnRH) neurons. Eur J Neurosci. 2004;20(2):338-344.

49. Fujioka H, Yamanouchi K, Akema T, et al. The Effects of GABA on embryonic gonadotropin-releasing hormone neurons in rat hypothalamic primary culture. J Reprod Dev. 2007;53(2):323-331.

50. Suter KJ, Song WJ, Sampson TL, et al. Genetic targeting of green fluorescent protein to gonadotropin-releasing hormone neurons: characterization of whole-cell electrophysiological properties and morphology. Endocrinology. 2000;141(1):412-419.

51. Constantin S, Iremonger KJ, Herbison AE. In vivo recordings of GnRH neuron firing reveal heterogeneity and dependence upon GABAA receptor signaling. J Neurosci. 2013;33(22):9394-9401.

52. Vannelli GB, Ensoli F, Zonefrati R, et al. Neuroblast long-term cell cultures from human fetal olfactory epithelium respond to odors. $J$ Neurosci. 1995;15(6):4382-4394.

53. Barni T, Maggi M, Fantoni G, et al. Sex steroids and odorants modulate gonadotropin-releasing hormone secretion in primary cultures of human olfactory cells. J Clin Endocrinol Metab. 1999;84(11):4266-4273.

54. Romanelli RG, Barni T, Maggi M, et al. Role of endothelin-1 in the migration of human olfactory gonadotropin-releasing hormonesecreting neuroblasts. Endocrinology. 2005;146(10):4321-4330.
55. Hu Y, Poopalasundaram S, Graham A, et al. GnRH neuronal migration and olfactory bulb neurite outgrowth are dependent on FGF receptor 1 signaling, specifically via the PI3K p110alpha isoform in chick embryo. Endocrinology. 2013;154(1):388-399.

56. Morelli A, Marini M, Mancina R, et al. Sex steroids and leptin regulate the "first Kiss" (KiSS 1/G-protein-coupled receptor 54 system) in human gonadotropin-releasing-hormone-secreting neuroblasts. $J$ Sex Med. 2008;5(5):1097-1113.

57. Morelli A, Fibbi B, Marini M, et al. Dihydrotestosterone and leptin regulate gonadotropin-releasing hormone $(\mathrm{GnRH})$ expression and secretion in human GnRH-secreting neuroblasts. J Sex Med. 2009;6(2):397-407.

58. Morelli A, Comeglio P, Sarchielli E, et al. Negative effects of high glucose exposure in human gonadotropin-releasing hormone neurons. Int J Endocrinol. 2013;2013:684659.

59. Sarchielli E, Comeglio P, Squecco R, et al. Tumor necrosis factor alpha impairs kisspeptin signaling in human gonadotropin-releasing hormone primary neurons. J Clin Endocrinol Metab. 2016;102(1):46-56.

60. Zhang G, Li J, Purkayastha S, et al. Hypothalamic programming of systemic ageing involving IKK-beta, NF-kappaB and GnRH. Nature. 2013;497(7448):211-216.

61. Salvi R, Arsenijevic Y, Giacomini M, et al. The fetal hypothalamus has the potential to generate cells with a gonadotropin releasing hormone (GnRH) phenotype. PLoS One. 2009;4(2):e4392.

62. Lund C, Pulli K, Yellapragada V, et al. Development of gonadotropinreleasing hormone-secreting neurons from human pluripotent stem cells. Stem Cell Reports. 2016;7(2):149-157.

63. Poliandri A, Miller D, Howard S, et al. Generation of kisspeptinresponsive GnRH neurons from human pluripotent stem cells. Mol Cell Endocrinol. 2017;447:12-22. 